\title{
PERFIL ELECTROFORÉTICO Y CALIDAD MICROBIOLÓGICA DE LA HARINA DE LOMBRIZ Eisenia fetida
}

\section{ELECTROPHORETIC PROFILE AND MICROBIOLOGICAL QUALITY FLOUR FROM THE WORM Eisenia fetida}

\author{
Rosa Alba Vielma R. (1), David Rosales, (3), Yolima Rosales (2), \\ Ana Luisa Medina (1), Juana Villarreal (1)
}

(1) Departamento de Ciencia de los Alimentos (Grupo de Ecología y Nutrición)

(2) Departamento de Microbiología y Parasitología, Facultad de Farmacia, Sector Campo de Oro, detrás del HULA.

(3) Departamento de Biología, Laboratorio de Enzimología, Facultad de Ciencias, La Hechicera,

Universidad de Los Andes, Mérida-Venezuela.

\begin{abstract}
An electrophoretic and microbiological study [more probable number (NMP), total (CT) and fecal coliforms (CF); aerobic-mesophils bacteria (BAM), molds and yeasts] in worm's flour of Eisenia fetida was carried out. In the electrophoretic profiles using gels of standard concentration, different protein fractions with molecular weights between 39.6 and $43.5 \mathrm{kDa}$ were separated. When gels with growing gradient of concentration were used, proteins with higher molecular weights (124.4 and $106.8 \mathrm{kDa}$ ) were separated with more detail. The protein characterization using different electrophoretic systems used in this study allows studying different protein fractions that could have a nutritional importance. The counts of BAM, CT, CF, molds and yeasts in this flour were low, indicating an innocuous product. With the use of this non-conventional resource, an interesting field of investigation begins involving food enrichment, representing an alternative at the industrial level.
\end{abstract}

Key words: Eisenia fetida, proteins, electrophoretic, microbiological.

Este trabajo fue recibido el 10 de Diciembre de 2007 y aceptado para ser publicado el 2 de Junio de 2008.

\section{INTRODUCCIÓN}

La lombricultura ha despertado en los últimos años un gran interés, por su repercusión en el ámbito nutricional y ecológico. Esta biotecnología utiliza la lombriz Eisenia fetida como una alternativa de reciclaje de desechos orgánicos de diferentes orígenes y como una fuente no convencional de proteínas y otros nutrientes, a bajo costo $(1,2)$.

La harina de lombriz, contiene proteínas (> $60 \%$ p/p, base seca), aminoácidos y ácidos grasos esenciales $(1,3-7)$, vitaminas y minerales importantes en la nutrición humana $(5,8)$.

Es de resaltar que, este recurso no convencional se podría utilizar como una alternativa nutricional, dado que contiene los elementos esenciales para la alimentación humana, así como para la formulación de alimentos balanceados para animales, especialmente los peces de agua fría, ya que estos son muy exigentes, dentro de sus requerimientos básicos. Los mismos para su desarrollo necesitan $40 \%$ de proteínas, de aminoácidos y ácidos grasos esenciales, vitaminas y minerales (9). También en México se han realizado estudios utilizando la harina de lombriz mezclada con harina de trigo y otros ingredientes para preparar galletas llamadas "lombretinas" para alimentación de niños (10). Además, ha sido ampliamente usada para la alimentación animal como cerdos (3), aves de corral y truchas arco iris (11-13).

Por otra parte, es importante destacar, que en el departamento de Ciencias de Alimentos de la Facultad de Farmacia de la Universidad de Los Andes, se llevan a cabo varias líneas de investigación, dentro de ellas, "La lombricultura como fuente de nutrición animal", la cual esta financiada por el Fondo Nacional de Investigaciones Científicas y Tecnológicas (FONACIT) con el código N ${ }^{\circ}$ G-200-5000-869". En este proyecto, se están desarrollando varios bioensayos con la harina 
de lombriz utilizando diferentes modelos de animales de experimentación (truchas y ratones), donde se han obtenido resultados interesantes en lo que se refiere a la formulación de dietas apropiadas para la nutrición animal.

El objetivo de este trabajo fue realizar un estudio del perfil electroforético utilizando geles de concentración estándar y de gradiente creciente para separar las diferentes proteínas presentes en la harina de lombriz $\mathrm{y}$, evaluar la calidad microbiológica en base al número mas probable (NMP) de coliformes totales (CT) y fecales (CF), recuento estándar de bacterias aerobias-mesófilas (BAM), mohos y levaduras, en muestras de harina de lombriz.

\section{MATERIALES Y MÉTODO}

Muestras: Se utilizó la lombriz Eisenia fetida, criada en un lombricultivo ubicado en el herbario de la Facultad de Farmacia y Bioanálisis de la Universidad de Los Andes. Se seleccionaron 500 lombrices adultas provenientes de diferentes estratos de la pila de compostaje de desechos orgánicos. Para el lavado de las lombrices se siguió la metodología de Velásquez et al., 1986a (1). La obtención de la harina liofilizada (HL) fue realizada luego de congelar las lombrices con nitrógeno líquido y posteriormente colocadas en un liofilizador a $-40{ }^{\circ} \mathrm{C}$. En cuanto a la preparación de la harina secada en estufa (HSE) las lombrices fueron lavadas según técnica de Velásquez et al., 1986a (1), sacrificadas mediante shock osmótico con una solución de $\mathrm{NaCl}$ al $4 \%$ y secadas durante 9 horas en estufa a $60^{\circ} \mathrm{C}$. Finalmente las lombrices secas se molieron hasta obtener un producto homogéneo.

Equipos: Equipo de electroforesis vertical Hoefer Mighty Small SE250/SE20. Equipo de electroforesis con sistema de gradiente Hoefer SE 600 Estándar Vertical Units run gels de $24 \mathrm{~cm}$ de longitud. Fuente de poder LKB Bromma 2197 power suply. Liofilizador Freezee dry system/LypH Lock 4,5.

\section{Tratamiento de las muestras}

Lisado proteico de lombriz cruda (LPLC): Se homogeneizó en un mortero $1 \mathrm{~g}$ de lombrices y se le agregó aproximadamente $1 \mathrm{~g}$ de carburo de silicio, 2 $\mathrm{mL}$ de buffer de inhibidores de proteasas. Las muestras fueron transferidas a tubos eppendorf y centrifugadas a $14000 \mathrm{rpm}$ por $5 \mathrm{~min}$. Los sobrenadantes fueron homogeneizados y luego sonicados aproximadamente a 10 pulsaciones durante $4 \mathrm{~min}$ en hielo. Posteriormente las muestras fueron nuevamente transferidas a tubos eppendorf y centrifugadas a $14000 \mathrm{rpm}$ durante $15 \mathrm{~min}$. Los sobrenadantes obtenidos fueron definidos como
LPLC.

Lisado proteico de la harina de lombriz liofilizada (LPHL1) y secada en estufa (LPHSE1): Se pesaron por duplicado $10 \mathrm{mg}$ de HL y HSE respectivamente, y se trasvasaron a tubos eppendorf. Las muestras fueron colocadas en hielo, agitadas en el vortex y homogeneizadas siguiendo la metodología descrita anteriormente para el LPLC. Los lisados proteicos obtenidos fueron definidos como LPHL1 y LPHSE1. Estas muestras se utilizaron para el análisis en geles de concentración estándar ( $8 \mathrm{~cm}$ de ancho por 7,5 cm de largo).

Lisado proteico de la harina de lombriz liofilizada (LPHL2) y secada en estufa (LPHSE2): Se pesaron por duplicado $50 \mathrm{mg}$ de HL y HSE respectivamente, y se trasvasaron a tubos eppendorf. Las muestras fueron colocadas en hielo, se agitaron en el vortex y se homogeneizaron siguiendo la metodología antes mencionada para el LPLC. Los lisados proteicos obtenidos fueron definidos como LPHL2 y LPHSE2. Estas muestras se utilizaron para el análisis en geles de concentración estándar (16 cm de ancho por $15 \mathrm{~cm}$ de largo).

Análisis electroforético con geles de concentración estándar (SDS-PAGE) $(8 \mathrm{~cm}$ de ancho por 7,5 cm de largo): Para la caracterización de las proteínas presentes en la harina de lombriz (HL y HSE) y lombriz cruda fueron preparados geles de poliacrilamida al $12,5 \%$ usando como medio desnaturalizante SDS-2mercaptoetanol según técnica de Laemmli, 1970 (14) y un estándar de peso molecular Bio-Rad Laboratorios: albúmina bovina (66,0 kDa), albúmina de huevo (45,0 $\mathrm{kDa})$, gliceraldehido $3 \mathrm{PDH}(36,0 \mathrm{kDa})$, anhidrasa carbónica $(29,0 \mathrm{kDa})$, tripsinógeno $(24,0 \mathrm{kDa})$, inhibidor de tripsina $(20,1 \mathrm{kDa})$ y $\alpha$-lactoalbúmina $(14,2 \mathrm{kDa})$ como referencia. La migración se realizó en un equipo de electroforesis vertical Hoefer Mighty Small SE250/ SE20 a $26 \mathrm{~mA}$ durante $1 \mathrm{~h}$ en un buffer Tris-glicinaSDS a pH 8,3.

Análisis electroforético con geles de gradiente creciente de concentración (SDS-PAGE) $(16 \mathrm{~cm}$ de ancho por $15 \mathrm{~cm}$ de largo): Para la determinación de pesos moleculares superiores a $66,0 \mathrm{kDa}$, fue utilizada un sistema de gradiente de gel acrilamida a una concentración 7,5\%-15\% con SDS-2-mercaptoetanol como medio desnaturalizante según metodología de Laemmli, de 1970 (14) y un patrón de peso molecular LMW 170446-01 Pharmacia Biotech: fosforilasa b (94 kDa), albúmina de suero bovino (67 kDa), anhidrasa carbónica (30 kDa), inhibidor de tripsina de granos de soya (20,1 kDa) y $\alpha$-lactoalbúmina $(14,4 \mathrm{kDa})$. La migración se realizó en un equipo de electroforesis con sistema de gradiente Hoefer SE600 Estándar Vertical Units de 24 $\mathrm{cm}$ de longitud a $40 \mathrm{~mA}$ durante $3 \mathrm{~h}$ en un buffer Tris- 
glicina-SDS a pH 8,3.

Todos los electroforogramas fueron fijados y coloreados usando solución de azul brillante Coomassie R-250 al 0,1\% (p/v) con ácido tricloroacético (TCA) y decolorados según protocolo de Girardet (15).

Para la cuantificación de los pesos moleculares de las proteínas usando geles de acrilamida-bisacrilamida, se realizó una curva patrón para cada uno de geles obtenidos. La elaboración de esta curva fue obtenida midiendo los Rf tanto para el patrón como para las muestras de acuerdo a la siguiente ecuación (16):

$$
\mathbf{R}=\frac{\text { distancia }(\mathrm{cm}) \text { recorrida por } \mathbf{~} \text { migración } \mathbf{d} \mathbf{~} \mathbf{~ p r o t e i ́ n a ~}}{\text { distancia }(\mathrm{cm}) \text { recorrida por } \mathbf{a} \text { migración del azul d bromofenol }}
$$

Análisis de calidad microbiológico: Se pesaron $10 \mathrm{~g}$ de HL y $10 \mathrm{~g}$ de HSE y se disolvieron en $90 \mathrm{~mL}$

\section{FIGURA 1}

Electroforesis en geles de poliacrilamida en condiciones desnaturalizantes SDS-PAGE

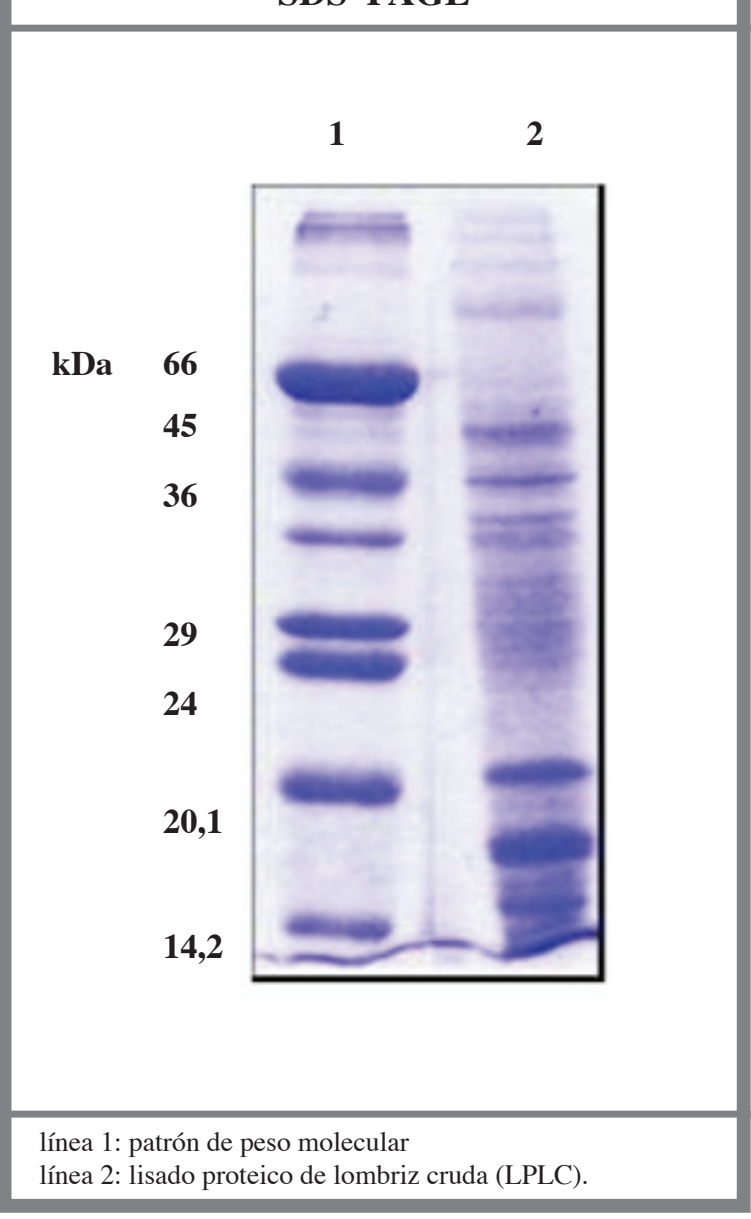

de agua peptonada cuya concentración final fue $0,1 \mathrm{~g} /$ $\mathrm{mL}$. De esta solución fueron preparadas soluciones con concentraciones finales de $0,01 \mathrm{~g} / \mathrm{mL}$ y $0,001 \mathrm{~g} / \mathrm{mL}$. La metodología utilizada para este análisis fue la del número mas probable (NMP) para coliformes totales (CT) y fecales $(\mathrm{CF})$, contaje estándar de bacterias aerobiasmesófilas (BAM), mohos y levaduras recomendada por la APHA (17).

\section{RESULTADOS Y DISCUSIÓN}

\section{Análisis electroforético con geles de} concentración estándar (SDS-PAGE)

Las figuras 1 y 2 muestran las diferentes bandas de las proteínas de los lisados pertenecientes a LPLC, LPHL1 y LPHSE1, a través de los cuales fueron calcu-

\section{FIGURA 2}

Electroforesis en geles de poliacrilamida en condiciones desnaturalizantes SDS -PAGE. Comparación de lisados proteicos de harina de lombriz

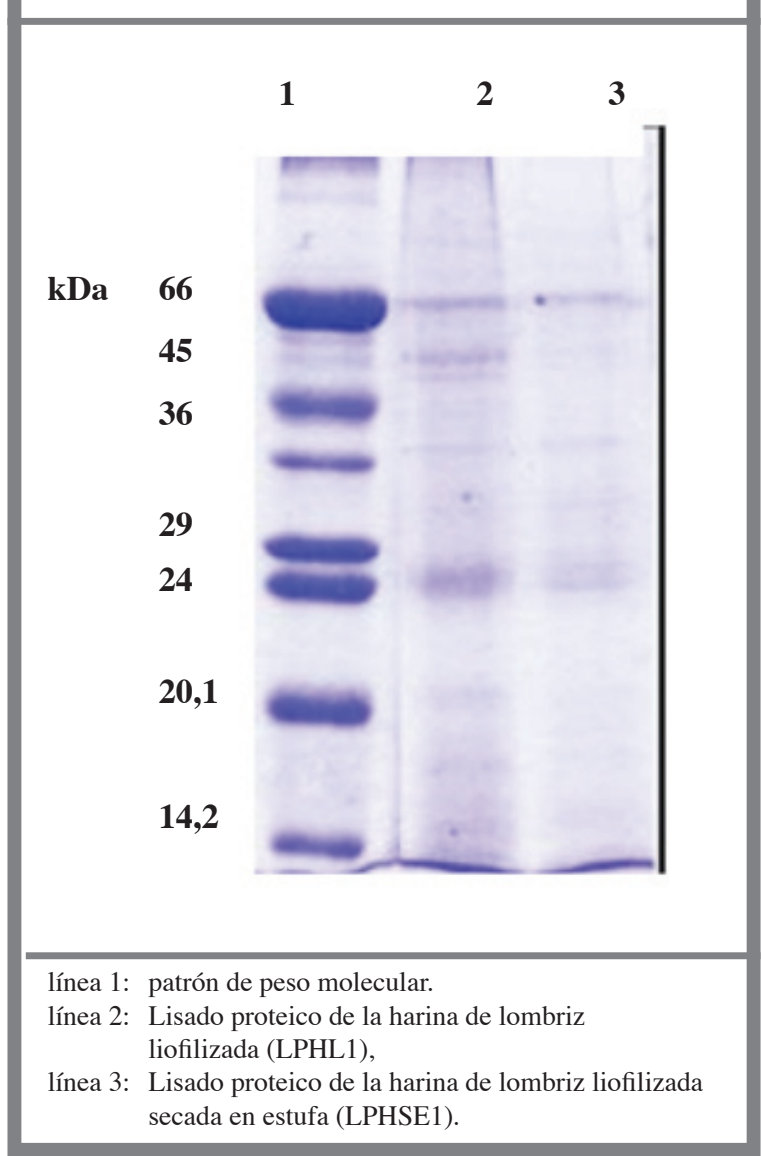


lados sus pesos moleculares (tabla 1).

Es de resaltar, que en el LPLC se determinaron los pesos moleculares de aproximadamente diecinueve proteínas, donde siete proteínas (*) se encontraron en la misma posición que en la corrida de las dos muestras de harinas (LPHL1 y LPHS1), lo que indicó presumiblemente que estas fracciones no fueron afectadas por los métodos de secado. Sin embargo, para los lisados de las harinas (LPHL1 y LPHSE1) se perdieron varias de estas fracciones (tabla 1), por lo que se infirió que el método de secado de la lombriz influyó en la determinación de las proteínas provocando desnaturalización de algunas fracciones proteicas (18-21).

Dentro de los pesos moleculares obtenidos en el LPLC se cuantificaron bandas proteicas con pesos moleculares de 46,0; 35,7 y 21,3 kDa (figura 1 y tabla $1)$, los cuales se aproximaron con las bandas proteicas del patrón de peso molecular de 45; 36 y 20,1 kDa correspondientes a la albúmina de huevo, gliceraldehido 3
PDH e inhibidor de tripsina, respectivamente.

Otras proteínas obtenidas fueron las de 63,9 y 29,7 kDa en las muestras de los LPLC, LPHL1 y LPHSE1; y 15,0 kDa en los LPHL1 y LPHSE1 (tabla 1), que se acercaron a la albúmina bovina, tripsinógeno y $\alpha$-lactoalbúmina, respectivamente del patrón de peso molecular (figura 2).

También se obtuvo una proteína de peso molecular de 24,7 kDa que se consiguió en todos los lisados proteicos (tabla 1), aproximándose a la subunidad S-globulina de $25 \mathrm{kDa}$ presente en la harina de soya reportada por Wu et al., (22) y otra banda proteica con un peso molecular de 14,8 kDa (LPLC) (tabla 1) que se acercó a la $\alpha$-lactoalbúmina cuyo peso molecular fue de 14,2 kDa. Closs (23), demostró que el lactosuero posee un comportamiento emulsificante determinado por la mezcla de $70 \%$ de $\beta$-lactoglobulina y $30 \%$ de $\alpha$-lactoalbúmina. La obtención de la banda que mostró un peso molecular similar a la $\alpha$-lactoalbúmina, podría

\section{TABLA 1}

\section{Peso moleculares de las proteínas del LPLC, LPHL1 y LPHSE1 en gel de electroforesis SDS-PAGE (calculados a partir de las figuras 1 y 2).}

\begin{tabular}{ccc} 
LPLC (kDa) & LPHL1 (kDa) & LPHSE1 (kDa) \\
\hline 91,1 & 90,0 & 90,0 \\
$84,1^{*}$ & $84,1^{*}$ & $84,1^{*}$ \\
$77,5^{*}$ & $77,5^{*}$ & $77,5^{*}$ \\
63,9 & 72,1 & 72,1 \\
57,0 & 63,9 & 63,9 \\
50,7 & 54,5 & 54,5 \\
46,0 & 49,7 & 49,7 \\
43,8 & 43,5 & 43,5 \\
$39,6^{*}$ & $39,6^{*}$ & $39,6^{*}$ \\
35,7 & 32,9 & 32,9 \\
$29,7^{*}$ & $29,7^{*}$ & $29,7^{*}$ \\
$24,7^{*}$ & 25,9 & 25,9 \\
23,5 & $24,7^{*}$ & $24,7^{*}$ \\
21,3 & $16,8^{*}$ & $16,8^{*}$ \\
$16,8^{*}$ & 15,8 & 15,8 \\
16,1 & 15,4 & 15,4 \\
15,3 & 15,1 & 15,1 \\
$15,0^{*}$ & $15,0^{*}$ & $15,0^{*}$ \\
14,8 & --- & --
\end{tabular}


resultar interesante en cuanto a sus propiedades funcionales, por lo tanto, sería necesario realizar un estudio mas minucioso al respecto para una posible aplicación tecnológica de estas proteínas.

\section{Análisis electroforético con gradiente} creciente de concentración SDS-PAGE

En las figuras 3 y 4 fueron distinguidas aproximadamente 24, 20 y 16 bandas proteicas correspondientes a los LPLC, LPHL2 y LPHSE2 respectivamente. Ocho proteínas se observaron nuevamente en el LPLC de la Eisenia fetida (tabla 2), y se encontraron en la misma posición que en la corrida de las dos muestras de harinas de los LPHL2 y LPHSE2, confirmando una vez más, que estas fracciones no fueron afectadas por los métodos de secado. Algunas de estas bandas proteicas son superiores

\section{FIGURA 3}

Electroforesis en SDS-PAGE con gradiente creciente de concentración $(7,5 \%-15 \%$ de acrilamida) en el lisado proteico de lombriz cruda (LPLC)

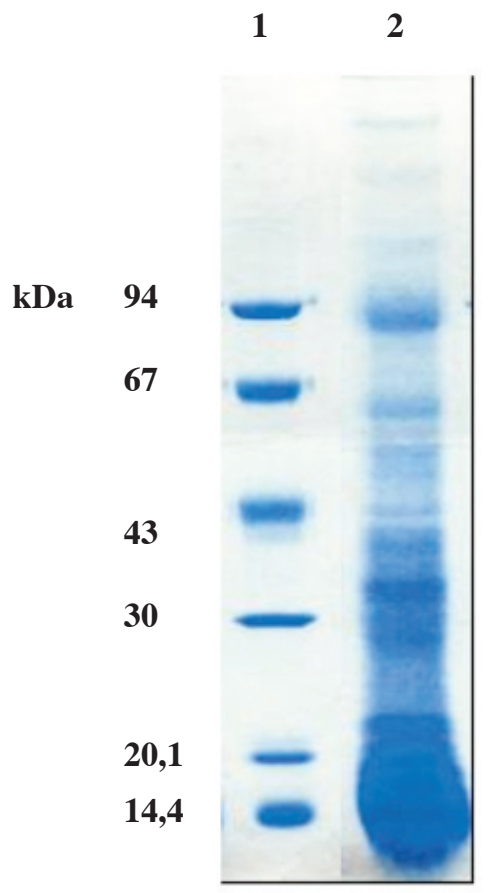

línea 1: patrón de peso molecular,

línea 2: (LPLC) a las de $94,0 \mathrm{kDa}$ (patrón de peso molecular), como las de 124,4; 106,8 kDa (LPLC, LPHL2 y LPHSE2); 109,6 kDa (LPLC) y 96,0 kDa (LPHL2 y LPHSE2) (tabla 2), cuyos pesos moleculares fueron semejantes a los de la glutenina de alto peso molecular (G-APM) que tiene un rango de 80-120 kDa, la cual juega un papel importante en la industria panificadora porque contribuyen a la elasticidad (fuerza) del gluten (24).

Ciertas bandas proteicas se aproximaron con las del estándar de peso molecular, entre las cuales están las de 93,4 kDa (LPLC); 96,0 kDa (LPHL2 y LPHSE2), 67,6; 44,1 y 19,5 kDa (LPLC, LPHL2 y LPHSE2) (Tabla II), que corresponden a la fosforilasa b (94 kDa), albúmina de suero bovino $(67, \mathrm{kDa})$, ovoalbúmina $(43 \mathrm{kDa})$ e inhibidor de tripsina $(20,1 \mathrm{kDa})$ respectivamente.

Las propiedades funcionales son de gran interés en

\section{FIGURA 4}

Electroforesis en geles de poliacrilamida en condiciones desnaturalizantes SDS-PAGE con gradiente creciente de concentración (7,5\%-15 \% de acrilamida); Comparación de lisados proteicos de harina de lombriz

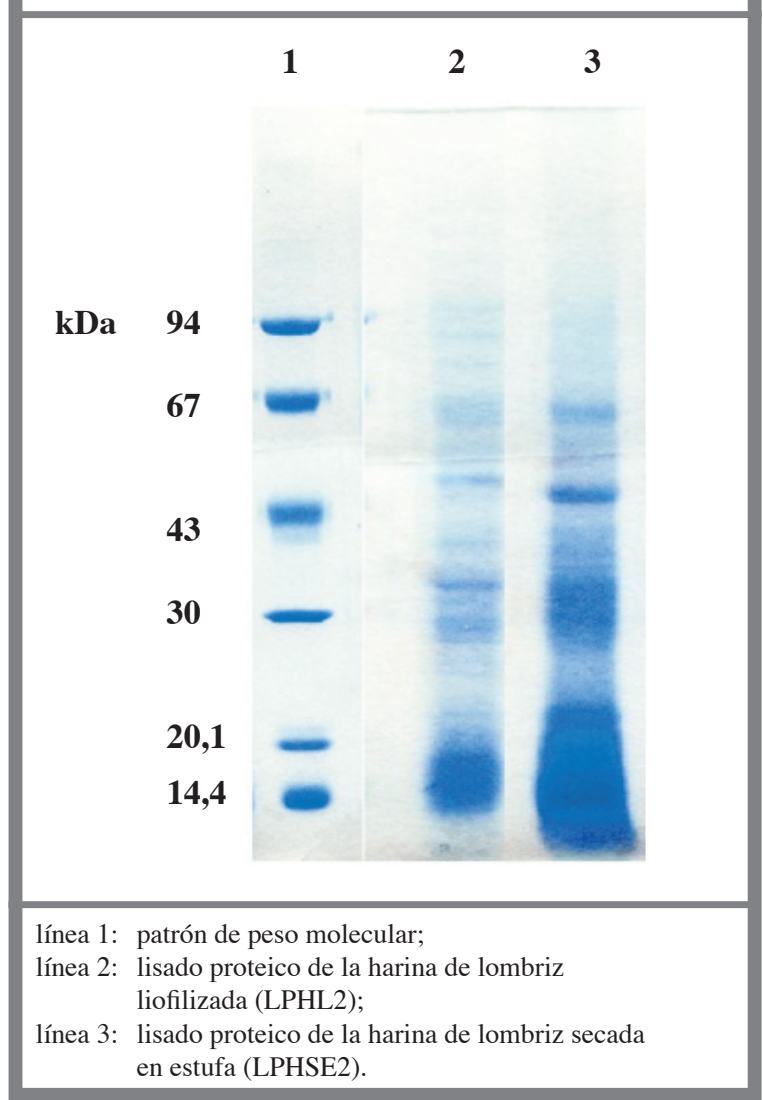


la industria agroalimentaria, debido a que la búsqueda de nuevas fuentes proteicas no tradicionales con alto valor nutritivo y propiedades tecno-funcionales es crucial para la investigación actual.

Otros valores de pesos moleculares obtenidos en este trabajo, fueron de 39,6 kDa (LPLC, LPHL1 y LPHSE1) (tabla 1), 40,0 kDa en LPHL2 y LPHSE2; 44,1 y 19,5 kDa (LPLC, LPHL2 y LPHSE2) (tabla 2), los cuales se aproximaron a los pesos moleculares de las fracciones proteicas reportadas por Roch et al., (25) aislados del fluido coelémico de la Eisenia fetida ubicadas entre 45, 40 y $20 \mathrm{kDa}$ con propiedad antibacteriana. Sin embargo
Hirigoyenberry et al., (26), utilizó las de 45 y 40 kDa para realizar estudios inmunológicos. Asimismo, se lograron separar dos proteínas en los LPLC con pesos moleculares correspondientes a 23,2 kDa (tabla 1) y $33,4 \mathrm{kDa}$ (tabla 2). Estos resultados son compatibles a los reportados por Hrzenjak et al., (27), que fueron de 34 y 23 kDa obtenidos de la fracción PI y PII respectivamente del complejo glicoliproteína (G-90), aislado del tejido de la lombriz Eisenia fetida, el cual exhibe actividad fibrinolítica y anticoagulante.

Estos resultados sugieren, que las diferentes fracciones proteicas analizadas utilizando estos dos sistemas

TABLA 2

Pesos moleculares de las proteínas del LPLC, LPHL2 y LPHSE2 en gel de electroforesis SDS-PAGE con sistema de gradiente.

\begin{tabular}{ccc}
\hline LPLC (kDa) & LPHL2 (kDa) & LPHSE2 (kDa) \\
\hline $124,4^{*}$ & $124,4^{*}$ & $124,4^{*}$ \\
109,6 & $106,8^{*}$ & $106,8^{*}$ \\
$106,8^{*}$ & 96,0 & 96,0 \\
93,4 & 88,3 & 88,3 \\
90,8 & 76,4 & 76,4 \\
74,1 & $67,6^{*}$ & $67,6^{*}$ \\
$67,6^{*}$ & 61,6 & 54,1 \\
63,5 & 52,3 & $44,1^{*}$ \\
57,7 & 48,9 & 40,0 \\
55,9 & $44,1^{*}$ & 33,4 \\
45,7 & 40,0 & $30,1^{*}$ \\
$44,1^{*}$ & 34,6 & $28,1^{*}$ \\
37,1 & 32,2 & 24,6 \\
34,6 & $30,1^{*}$ & $19,5^{*}$ \\
33,4 & $28,1^{*}$ & $18,8^{*}$ \\
$30,1^{*}$ & 27,2 & 18,3 \\
28,1 & 25,4 & \\
25,4 & 23,2 & \\
$19,5^{*}$ & 21,9 & \\
$18,8^{*}$ & 19,5 & \\
18,5 & & \\
$18,8^{*}$ & & \\
18,0 & & \\
17,9 & & \\
\hline$*$ pesos moleculares encontrados en todos los lisados proteicos de la lombriz Eisenia fetida & \\
\hline & & \\
\hline
\end{tabular}


electroforéticos confirman el gran interés que podría tener la lombriz en el campo nutricional, tecnológico y farmacológico. Por lo tanto, se recomienda continuar el estudio de estas proteínas no convencionales en este tipo de muestra.

\section{Análisis microbiológico}

El contenido de BAM fue mayor en la HSE que en la HL (tabla 3), atribuyendo esta diferencia al método de secado, lo que pudo originar mayor multiplicación microbiana en la HSE. Con respecto al contenido de mohos y levaduras fue mayor en la HL que en la HSE. Este resultado podría estar asociado a una posible contaminación externa durante el secado de la harina. Sin embargo, estos valores se podrían considerar satisfactorios, si se comparan con los reportados por Velásquez et al., (1), quienes trabajaron con este tipo de lombriz utilizando un tratamiento térmico de 80,105 y $120{ }^{\circ} \mathrm{C}$ por espacio de $1 \mathrm{~h}$ previo al secado (tabla 4 ).

Es importante destacar, que los resultados obtenidos en este tipo de análisis se encuentran dentro de los límites establecidos en algunas normas tales como la Comisión Venezolana de Normas Industriales (COVENIN N² 217-2001 y 2703-90) (28), (29) y la Normativa de Control Oficial y Seguridad Alimentaria en España R.D. 1286/1984, R.D. 1094/1987 y Orden de 2 de agosto de 1991 (30) reportadas en la tabla 5 para alimentos tradicionales. Además, si se comparan, con los valores reportados por FEDNA, 2003 (31), la cantidad total de aerobios para harina de carne fueron $<106$, es decir, que estos valores son mayores a los obtenidos en este trabajo (tabla 3).

Igualmente la cantidad de mohos y levaduras fue inferior al compararlo con los reportados por Velásquez y Camba, 2002 (32) para la harina de trigo panificable que fue de $500 \mathrm{UFC} / \mathrm{g}$. Lo relevante de este estudio, es que no existen referencias certificadas de estos valores en harinas de lombriz, por lo que los mismos fueron comparados con las normas COVENIN y españolas de algunas harinas tradicionales.

Según Frazier (33), una humedad en las harinas para consumo humano inferior al 13\% impide el desarrollo de todos los microorganismos. Sin embargo un contenido de agua del orden del $15 \%$ permite el desarrollo abundante de moho y si excede del 17\%, el de mohos y de ciertas bacterias.

Este trabajo ofrece un aporte interesante, puesto que el contenido de humedad de las HL $(11,3 \%)$ y HSE $(13,5 \%)(34)$, no es favorable para el desarrollo bacteriano y de hongos; por lo tanto, ésta harina no representa ningún riesgo microbiológico, garantizando los estudios nutricionales.

\section{TABLA 3}

Análisis microbiológico de la harina de lombriz liofilizada (HL) y secada en estufa (HSE)

$\begin{array}{cccccc}\text { Muestra } & \begin{array}{c}\text { BAM }^{1} \\ \left(\mathbf{U F C}^{4} / \mathbf{g}\right)\end{array} & \begin{array}{c}\mathbf{C T}^{\mathbf{2}} \\ (\mathbf{N M P} / \mathbf{m L})\end{array} & \begin{array}{c}\mathbf{C F}^{\mathbf{3}} \\ (\mathbf{N M P} / \mathbf{m L})\end{array} & \begin{array}{c}\text { Mohos } \\ (\mathbf{U F C} / \mathbf{g})\end{array} & \begin{array}{c}\text { Levaduras } \\ (\mathbf{U F C} / \mathbf{g})\end{array} \\ \mathrm{HL} & 3,3 \times 10^{4} & <3 & <3 & 2,0 \times 10^{2} & 4 \times 10^{2} \\ \mathrm{HSE} & 7,5 \times 10^{4} & <3 & <3 & 1,2 \times 10^{2} & <1\end{array}$

Bacterias aerobias mesófilas ${ }^{1}$; Coliformes totales ${ }^{2}$; Coliformes fecales ${ }^{3}$; Unidades formadoras de colonias ${ }^{4}$; Número mas probable ${ }^{5}$.

TABLA 4

Análisis microbiológico de harina de lombriz Eisenia fetida reportado por Velásquez et al. (1)

\begin{tabular}{cccc} 
Recuento & $\mathbf{8 0}^{\circ} \mathbf{C}$ & $\mathbf{1 0 5}^{\circ} \mathbf{C}$ & $\mathbf{1 2 0}^{\circ} \mathbf{C}$ \\
\hline BAM (UFC/g) & $8,2 \times 10^{5}$ & $5,8 \times 10^{5}$ & $8,7 \times 10^{4}$ \\
CT (UFC/g) & 1450 & 1100 & 45 \\
Moho y Levaduras (UFC/g) & $1,2 \times 10^{3}$ & $3,0 \times 10^{2}$ & $3,0 \times 10^{2}$
\end{tabular}




\section{RESUMEN}

Se realizó un estudio electroforético y microbiológico [número más probable (NMP), coliformes totales $(\mathrm{CT})$ y fecales $(\mathrm{CF})$; bacterias aerobias-mesófilas (BAM), mohos y levaduras] en harina de lombriz Eisenia fetida. En los perfiles electroforéticos con geles de concentración estándar se separaron diferentes fracciones proteicas con pesos moleculares comprendidos entre 39,6 y $43,5 \mathrm{kDa}$, valores similares a los reportados por otros investigadores. Cuando se usaron geles con gradiente creciente de concentración, se lograron separar en forma mas detallada proteínas con pesos moleculares más altos (124,4 y 106,8 kDa). En este estudio, la caracterización de proteínas utilizando distintos sistemas electroforéticos permitió analizar las diferentes fracciones proteicas que pudiesen tener una importancia nutricional. Los recuentos de BAM, CT, CF, mohos y levaduras en esta harina fueron bajos, lográndose un producto inocuo. Es importante destacar, que con la utilización de este recurso no convencional, se inicia un interesante campo de investigación en lo que se refiere al enriquecimiento de alimentos, representando una alternativa a nivel industrial.

Palabras claves: Eisenia fetida; proteínas, electroforético, microbiológico.
Dirigir la correspondencia a:

\section{Profesora}

Rosa Alba Vielma R.

Facultad de Farmacia.

Universidad de Los Andes.

Sector Campo de Oro, detrás del HULA.

Mérida 5101, Mérida, Venezuela.

Teléfono: 58-0274-2403473

Fax: 58-0274-2403474

E-mail: rosavvefr@yahoo.com

\section{BIBLIOGRAFÍA}

1. Velásquez L, Herrera C, Ibáñez I, Harina de lombriz. I Parte: Obtención, composición química, valor nutricional y calidad bacteriológica, Alimentos 1986a; 11(1):15-21.

2. Medina A, Araque J. Obtención, composición química, funcional, perfiles electroforéticos y calidad bacteriológica de la carne y harina de lombriz Eisenia foetida. Revista de la Facultad de Farmacia (ULA) 1999; 37:31-38.

3. Tacon AG, Stafford EA, Edwards CA. A preliminary investigation of the nutritive value of three terrestrial lumbricid worms for rainbow trout, Aquaculture 1983; 35:187-199.

\section{TABLA 5}

\section{Límites microbiológicos para algunas harinas y productos de pesca y derivados}

\begin{tabular}{|c|c|c|c|c|}
\hline Muestra & $\begin{array}{c}\text { BAM } \\
(\mathrm{UFC} / \mathrm{g})\end{array}$ & $\begin{array}{l}\text { Mohos } \\
\text { (UFC/g) }\end{array}$ & $\begin{array}{l}\text { Levaduras } \\
\text { (UFC/g) }\end{array}$ & Normas \\
\hline Harina de trigo & $\begin{array}{l}5,0 \times 10^{2}(\mathrm{~m}) \\
1,0 \times 10^{4}(\mathrm{M})\end{array}$ & -------- & ------ & $\begin{array}{l}\text { COVENIN } \\
(217-2001)\end{array}$ \\
\hline Harina integral de trigo & $\begin{array}{l}2,0 \times 10^{6}(\mathrm{~m}) \\
1,0 \times 10^{7}(\mathrm{M})\end{array}$ & $\begin{array}{l}1,0 \times 10^{2}(\mathrm{~m}) \\
1,0 \times 10^{4}(\mathrm{M})\end{array}$ & ------- & $\begin{array}{c}\text { COVENIN } \\
(2703-90)\end{array}$ \\
\hline Harinas y sémolas de trigo & $1,0 \times 10^{6}$ & $1,0 \times 10^{4}$ & ------- & $\begin{array}{l}\text { R.D. } \\
\text { 1286/1984 }\end{array}$ \\
\hline Cereales en copos o expandidos & $1,0 \times 10^{4}$ & $1,0 \times 10^{2}$ & $1,0 \times 10^{2}$ & $\begin{array}{c}\text { R.D. } \\
\text { 1094/1987 }\end{array}$ \\
\hline $\begin{array}{l}\text { Pesca y derivados (productos } \\
\text { seco-salados, salazones y desecados) }\end{array}$ & $1,0 \times 10^{5}$ & ------ & ----- & $\begin{array}{l}\text { Orden de } 2 \text { de } \\
\text { agosto de } 1991\end{array}$ \\
\hline
\end{tabular}


4. Velásquez L, Herrera C, Ibáñez I. Harina de lombriz. II Parte: Composición de ácidos grasos, factores antinutricionales y tratamiento térmico para control bacterial. Alimentos 1986b; 11(4):9-13.

5. Salazar E, Rojas C. Conferencias Curso Fundamental de Lombricultura. Aspectos Generales-Teoría. Asociación Colombiana de Lombricultores, Asolombriz, Grupo CorpoAndes, Mérida, Venezuela, 1992.

6. Vielma R, Ovalles J, León A, Medina A. Valor nutritivo de la harina de lombriz (Eisenia foetida) como fuente de aminoácidos y su estimación cuantitativa mediante cromatografía en fase reversa (HPLC) y derivatización precolumna con o-ftalaldehído (OPA). Ars Pharmaceutica 2003a; 44(1):43-48.

7. Vielma R, Usubillaga A, Medina A. Estudio preliminar de los niveles de ácidos grasos de la harina de lombriz (Eisenia foetida) mediante cromatografía de gases acoplada a espectrometría de masas, Revista de la Facultad de Farmacia (ULA) 2003b. 45(2):3944.

8. Vielma R, Carrero P, Rondón C, Medina A. Comparación del contenido de minerales y elementos trazas en la harina de lombriz (Eisenia foetida) utilizando dos métodos de secado, Saber 2007; 19(1):25-29.

9. Guillaume J, Kaushik S, Bergot P, Métailler R. Nutrition et alimentation des poissons et crustacés. INRA. 1999.

10. Ramírez M. Fabrican en IPN con lombrices de tierra galletas tan nutritivas como un filete de res. 2005. Recuperado en enero 25, 2007 disponible en http:// www.manualdelombricultura.com/wwwboard/wwwboard.html

11. Velásquez L, Herrera C. Aplicaciones de la harina de lombriz (Eisenia foetida) en nutrición animal: aves broilers; truchas arco-iris. Alimentos 1986; 11(4):52-55.

12. Ibáñez I, Herrera C, Oyarzún M, Velásquez L. Harina de lombriz. IV Parte: Evaluación nutricional en alimentación de truchas arco-iris. Alimentos 1991; 16(2):17-22.

13. Jadrijevic D, Varnero T, Carrasco A, López R. Utilización de la lombriz Eisenia foetida en la degración de guano animal. II. Guano de bovino y caprino. Avances en producción Animal 1991; 16(1-2): 189201.

14. Laemmli UK. Most commonly used discontinous buffer system for SDS electrophoresis, Nature 1970; 227:680-685.

15. Girardet JM, Sanogo T, Etienne L. Linden G. Fast protein chromatography purification of hydrophobic fraction of bovine milk protease-peptone and characterization by bidimensional electrophoresis. J Dairy Res 1991; 58:85-98.

16. Bollag, D, Rozycki M. Stuart E. Protein Methods. 2 th ed. Wiley-Liss, 1996.

17. American Public Health Association (APHA). Compendium of methods for the examination of food. 3 th ed. Washington, (USA), 1992, p. 25-245

18. Linden, G. Lorien,t D. Bioquímica Agroindustrial. 1era. ed. Acribia, Zaragoza-España, 1996.

19. Lawhon JT, Cater CM, Mattil KF. A whippable extract from gladness cottonseed flour, J Food Science 1972; 317:321.

20. Ahenkora K, Dadzie M, Osei-Bonsu P. Composition and funtional properties of raw heat processed velvet bean (Mucuna pruriens (L) DC. Var utilis) flours, Internat Food Science Technol 1999; 34:131-135.

21. Wang C, Johnson L. Funtional properties of hydrothermally cooked soy proteins products, J Am Oil Chem Soc 2001; 78(2) :189-195.

22. Wu WU, Hettiarachy NS, Qi M. Hydrophobicity, solubility and Emulsifying properties of soy protein peptides prepared by papain modification and ultrafiltration. JAOCS 1998; 75(7):845-850.

23. Closs B. Influence de la structure sur les propiètès de surface des protéines du lactosérum. [Tesis de Doctorado no publicada]. Universidad de Bourgogne, Escuela Nacional Superior de Biología Aplicada a la Nutrición y Alimentación (ENSBANA), DijonFrance, 1990, pp 242.

24. Martínez E, Espitia E, Benítez I, Peña R, Santacruz A. Villaseñor H. Efecto de gluteninas de alto peso molecular de los genomas A y B sobre propiedades reológicas y volumen de pan en trigos harineros. Agrociencia 2007; 41:153-160.

25. Roch P, Valembois P, Davant N, Lassagues M. Proteins analysis of earthworm coelomic fluid-II. Isolation and biochemical characterization of the Eisenia foetida andrei (EFAF), Comp Biochem Physiol 1981; 69B:829-836.

26. Hirogoyenberry F, Lassegues M, Roch P. Antibacterial activity of Eisenia fetida andrei coelomic fluid: Immunological study of the major antibacterial proteins. J Invertebrate Pathol 1992; 59:69-74.

27. Hrzenjak T, Popovic M, Bozic T, Grdisa M, Kobrehel D, Tiska-Rudman L. Fibrinolytic and anticoagulative activities from the earthworm Eisenia foetida. Comp Biochem Physiol 1998; 119B:825-832.

28. Comisión Venezolana de Normas Industriales (COVENIN). Harina de trigo, 4ta. Revisión (217). República Bolivariana de Venezuela, Ministerio de Desarrollo Social. Gerencia Sectorial de Registro y Control. Instituto Nacional de Higiene "Rafael 
Rángel". Caracas, Venezuela, 2001.

29. Comisión Venezolana de Normas Industriales (COVENIN). Harina Integradle trigo (2703). 1995. República Bolivariana de Venezuela, Ministerio de Desarrollo Social. Gerencia Sectorial de Registro y Control. Instituto Nacional de Higiene "Rafael Rángel” Caracas, Venezuela, 1990.

30. Normativa de Control Oficial y Seguridad Alimentaria en España. Recuperado en Febrero 8, 2007, disponible: http://www.acis-normativa.com/modules. php? name $=$ acis $\& I d=0205 \& I d 2=126 \mathrm{C} 13 / 06 / 05$.

31. FEDNA. Tablas FEDNA de composición y valor nutritivo de alimentos para la formulación de piensos compuestos. (2da. ed.). Madrid, España. C. de Blas, G.G. Mateos y P.G ${ }^{\text {a }}$. Rebollar ed. Fundación
Española para el Desarrollo de la Nutrición Animal. 2003, pp 423.

32. Velásquez J, Camba N. Diseño de un sistema de análisis de riesgos y puntos críticos de control (HACCP) para una línea de producción de harina de trigo panificable. Centro de Desarrollo Tecnológico Sustentable. Recuperado en Agosto 8, 2006, disponible: http://www.cdts.espol.edu.ec/htm/proy7. htm. 2002.

33. Frazier, WC. Microbiología de los Alimentos. 2 da. ed. Zaragoza-España, Acribia, 1976.

34. Vielma RA, Medina AL. Determinación de la composición química y estudios de solubilidad en la harina de la lombriz Eisenia foetida, Rev Fac Farmacia (ULA) 2006; 48(1):2-8. 